Marquette University

e-Publications@Marquette

Psychology Faculty Research and Publications

Psychology, Department of

$1-1-2005$

\title{
Medial Temporal Lobe Activity for Recognition of Recent and Remote Famous Names: an Event- Related fMRI Study
}

Kelli Douville

Rosalind Franklin University of Medicine and Science

John L. Woodard

Wayne State University

Michael Seidenberg

Rosalind Franklin University of Medicine and Science

Sarah K. Miller

Rosalind Franklin University of Medicine and Science

Catherine L. Leveroni

Rosalind Franklin University of Medicine and Science

See next page for additional authors

Accepted version. Neuropsychologia, Vol. 43, No. 5 (2005): 693-703. DOI. (C) 2005 Elsevier. Used with permission. 
Authors

Kelli Douville, John L. Woodard, Michael Seidenberg, Sarah K. Miller, Catherine L. Leveroni, Kristy A.

Nielson, Malgorzata Franczak, Piero Antuono, and Stephen M. Rao 


\title{
Medial Temporal Lobe Activity For Recognition Of Recent And Remote Famous Names: An Event-Related fMRI Study
}

\author{
Kelli Douville \\ Department of Neurology, Medical College of Wisconsin, \\ Milwaukee, WI \\ Department of Psychology, Finch University of Health \\ Sciences/The Chicago Medical School, North Chicago, IL \\ John L. Woodard \\ Department of Psychology, Finch University of Health \\ Sciences/The Chicago Medical School, North Chicago, IL \\ Michael Seidenberg \\ Department of Psychology, Finch University of Health \\ Sciences/The Chicago Medical School, North Chicago, IL \\ Sarah K. Miller \\ Department of Psychology, Finch University of Health \\ Sciences/The Chicago Medical School, North Chicago, IL \\ Catherine L. Leveroni \\ Department of Neurology, Medical College of Wisconsin, \\ Milwaukee, WI
}

[Neuropsychologia, Vol 43, No. 5 (2005): pg. 693-703. DOI. This article is (C Elsevier and permission has been granted for this version to appear in e-Publications@Marquette. Elsevier does not grant permission for this article to be further copied/distributed or hosted elsewhere without the express permission from Elsevier.] 
Department of Psychology, Finch University of Health Sciences/The Chicago Medical School, North Chicago, IL

\author{
Kristy A. Nielson \\ Department of Psychology, Marquette University, \\ Milwaukee, WI \\ Foley Center for Aging, Medical College of Wisconsin, Milwaukee, \\ WI \\ Malgorzata Franczak \\ Department of Neurology, Medical College of Wisconsin, \\ Milwaukee, WI \\ Piero Antuono \\ Department of Neurology, Medical College of Wisconsin, 9200 W. \\ Wisconsin Ave., Milwaukee, WI \\ Stephen M. Rao \\ Department of Neurology, Medical College of Wisconsin, \\ Milwaukee, WI
}

\begin{abstract}
Previous neuroimaging studies examining recognition of famous faces have identified activation of an extensive bilateral neural network [Gorno Tempini, M. L., Price, C. J., Josephs, O., Vandenberghe, R., Cappa, S. F., Kapur, N. et al. (1998). The neural systems sustaining face and proper-name processing. Brain, 121, 2103-2118], including the medial temporal lobe (MTL) and specifically the hippocampal complex [Haist, F., Bowden, G. J., \& Mao, H. (2001). Consolidation of human memory over decades revealed by functional magnetic resonance imaging. Nature Neuroscience, 4, 1139-1145; Leveroni, C. L., Seidenberg, M., Mayer, A. R., Mead, L. A., Binder, J. R., \& Rao, S. M. (2000). Neural systems underlying the recognition of familiar and newly learned faces. Journal of Neuroscience, 20, 878-886]. One model of hippocampal functioning in autobiographical, episodic memory retrieval argues that the hippocampal complex remains active in retrieval tasks regardless of time or age of memory (multiple trace theory, MTT), whereas another proposal posits that the hippocampal complex plays a time-limited role in retrieval of autobiographical memories. The current event-related fMRI study focused on the medial temporal lobe and its response to recognition
\end{abstract}

[Neuropsychologia, Vol 43, No. 5 (2005): pg. 693-703. DOI. This article is (C) Elsevier and permission has been granted for this version to appear in e-Publications@Marquette. Elsevier does not grant permission for this article to be further copied/distributed or hosted elsewhere without the express permission from Elsevier.] 
judgments of famous names from two distinct time epochs (1990s and 1950s) in 15 right-handed healthy older adults (mean age $=70$ years). A pilot study with an independent sample of young and older subjects ensured that the stimuli were representative of a recent and remote time period. Increased MR signal activity was observed on a bilateral basis for both the hippocampus and parahippocampal gyrus (PHG) during recognition of familiar names from both the recent and remote time periods when compared to nonfamous names. However, the impulse response functions in the right hippocampus and right PHG demonstrated a differential response to stimuli from different time epochs, with the 1990s names showing the greatest MR signal intensity change, followed by the 1950s names, followed by foils. The finding that recognition of famous names produced significant bilateral MTL activation regardless of time epoch relative to foils provides support for the MTT model. However, the finding of a temporal gradient in the right MTL also provides support for the HC model, given the greater MTL response associated with recently famous names relative to remotely famous names.

Keywords: Medial temporal lobe, Hippocampal complex, fMRI

\section{Introduction}

Renewed interest in characterizing the nature and extent of medial temporal lobe (MTL) involvement during semantic long-term memory retrieval has led to contrasting perspectives regarding the time course of MTL involvement in long-term memory retrieval. The two major models, the hippocampal consolidation (HC) model (Squire \& Alvarez, 1995) and multiple trace theory (MTT) model (Nadel \& Moscovitch, 1997), offer distinct predictions of MTL involvement during retrieval of autobiographical, episodic memories. The HC model posits a time-limited role of the hippocampal complex during memory consolidation: after a critical time period, retrieval is believed to be mediated by brain systems independent of the MTL. In contrast, the MTT model proposes that the hippocampal complex updates and enriches memories of autobiographical episodes throughout the life of the memory. However, both models offer similar predictions regarding semantic memory retrieval; specifically, the MTL would be expected to play a time-limited role. A temporal gradient would be predicted by both models, with recent memories being expected to activate the hippocampal complex more than remote memories. The majority of functional neuroimaging research to date has explored MTL activation for autobiographical memory tasks, but less study has been devoted to semantic memory. The present study investigates the role of MTL during recognition of famous names from distinctly different time

[Neuropsychologia, Vol 43, No. 5 (2005): pg. 693-703. DOI. This article is (C Elsevier and permission has been granted for this version to appear in e-Publications@Marquette. Elsevier does not grant permission for this article to be further copied/distributed or hosted elsewhere without the express permission from Elsevier.] 
epochs as a means of studying MTL activity during semantic long-term memory retrieval.

To date, the primary source of data for testing the validity of predictions made by these two models has come from clinical evaluations of the presence and extent of retrograde memory impairment following focal lesions of the temporal lobe. These studies suggest that multiple factors can determine the presence and nature of the observed temporal gradient, including the type of memory system examined (episodic autobiographical versus semantic public), stimulus characteristics (transient versus persistent fame), and extent and location of the temporal lobe lesion (Fujii, Moscovitch, \& Nadel, 2000). Specifically, it has been suggested that more extensive lesions of the MTL (beyond the hippocampal complex) tend to produce a more extensive and flat remote memory temporal gradient (Rempel-Clower, Zola, Squire, \& Amaral, 1996). Because the majority of these reports are based on single case or small group studies, and lesion characteristics are heterogeneous across these studies, it is difficult to draw firm conclusions based solely on human lesion data regarding the nature and extent of MTL activity in semantic long-term memory retrieval (Kopelman, 2000).

Functional neuroimaging techniques conducted on healthy individuals provide an alternative strategy for investigating the time course for MTL involvement in retrieval of information from long-term memory. In contrast to the extensive number of studies of anterograde memory (Cabeza \& Nyberg, 1997), only a few neuroimaging studies have specifically examined the activity of the MTL region during recall of information from different time epochs, and these studies have primarily focused on autobiographical episodic memory retrieval (Maguire, Henson, Mummery, \& Frith, 2001; Niki \& Luo, 2002; Piefke, Weiss, Zilles, Markowitsch, \& Fink, 2003; Tsukiura et al., 2002). This disparity stands in contrast to research in the clinical lesion literature in which remote memory has been investigated extensively using public semantic memory tasks as well as autobiographical memory. Furthermore, different neural regions may be relevant in mediating retrieval of autobiographical and public semantic memory (Fujii et al., 2000). Within the domain of semantic memory, person-identity (e.g., recognition of famous people) has been the most commonly employed measure used to study the existence of

[Neuropsychologia, Vol 43, No. 5 (2005): pg. 693-703. DOI. This article is (C) Elsevier and permission has been granted for this version to appear in e-Publications@Marquette. Elsevier does not grant permission for this article to be further copied/distributed or hosted elsewhere without the express permission from Elsevier.] 
a temporal gradient for remote memory. Functional neuroimaging studies examining familiar face recognition have commonly observed MTL activity (Kapur, Friston, Young, Frith, \& Frackowiak, 1995; Leveroni et al., 2000; Sergent, Zuck, Terriah, \& MacDonald, 1992), but these studies have not systematically examined MTL activity induced during recall of information from distinct time epochs associated with these familiar faces.

In the only published functional neuroimaging study to date to examine recent and remote semantic memory, Haist, Bowden, and Mao (2001) presented famous faces from six decades (1940s-1990s) to eight Ss (mean age $=65$ years). They observed a trend toward significantly increased activation in the right anterior hippocampus for famous faces from the recent decade. However, famous faces from the 1990s and 1980s produced increased activity in the right entorhinal cortex compared to famous faces from the previous four decades (1940s-1970s). The authors suggested that these data were supportive of the traditional time-limited role of the MTL system in long-term memory retrieval. In addition, they suggested that the hippocampal formation had a short temporal gradient relative to that observed in the entorhinal cortex which may play a more pivotal role in the consolidation process.

However, several methodological aspects of the Haist et al. (2001) study raise interpretive questions about their findings in relation to the role of MTL regions in remote memory retrieval. Haist et al. used a blocked design and asked subjects to recall the names of the faces being presented. The ability to recall the names of famous faces is known to be highly variable, particularly in older subjects (Maylor, 1990; Wahlin et al., 1993). Indeed, their post-scanning data indicated that name recall level was about $40 \%$ correct across the six decades. A blocked design does not provide a means to distinguish the MR signal activity for correct and incorrect trials. Furthermore, it is well established that there is a sequence of hierarchical stages, including face recognition and semantic identification, that precedes name recall in the face identification process (Bruce \& Young, 1986). In the absence of reaching the name recall stage for famous faces (about $60 \%$ of trials on average), it is quite likely that subjects were at varying (and unknown) points in the person recognition and identification system that precede name retrieval. Thus, the observed

[Neuropsychologia, Vol 43, No. 5 (2005): pg. 693-703. DOI. This article is (C Elsevier and permission has been granted for this version to appear in e-Publications@Marquette. Elsevier does not grant permission for this article to be further copied/distributed or hosted elsewhere without the express permission from Elsevier.] 
MR signal activation reported in this study could reflect this heterogeneity in processing stage.

A second important methodological issue concerns potential stimulus characteristics (other than age of memory), which may also be relevant for producing variation in MTL activity for remote and recent stimuli. This issue has not been the subject of systematic examination or control in most functional neuroimaging studies on this topic to date. For example, in the Haist et al. (2001) study, famous faces were selected from published biography yearbooks and there was no mention of procedures to match the stimuli across the six decades. It is quite possible that stimulus parameters, such as extent of familiarity or amount of semantic knowledge, could influence the presence or extent of MTL activity during retrieval. Indeed, a recent paper examining fMRI activity for recent and remote autobiographical events found increased activity within the MTL region, which peaked in the entorhinal region for positive contrasted with negative emotional valence autobiographical memories (Piefke et al., 2003).

The current paper reports the findings from an event-related fMRI study of MTL activity associated with identification of famous people in healthy older participants. Specifically, this study contrasted the MTL activation pattern for recognition of famous people's names from a distant time epoch (1950s) with the activation pattern for recognition of famous names from a more recent time period (1990s). Use of an event-related design permitted us to examine only trials of correct familiar name recognition and the resulting activation maps are not confounded by incorrect name recognition trials. The current study design also included a detailed and systematic approach to stimulus development that equated the famous name stimuli across the two time periods for familiarity and semantic knowledge. For the stimuli used in the present study, we conducted a preliminary study with a separate group of elderly subjects to identify famous names from a recent and remote time period that had comparable and high levels of recognition and also for whom a considerable amount of semantic information was accessible to the subjects. Thus, the objective of this study was to use an event-related fMRI design to examine MTL activity for famous names from two time epochs and to relate findings to the current discussion concerning the role of the MTL in long term memory retrieval.

[Neuropsychologia, Vol 43, No. 5 (2005): pg. 693-703. DOI. This article is (C Elsevier and permission has been granted for this version to appear in e-Publications@Marquette. Elsevier does not grant permission for this article to be further copied/distributed or hosted elsewhere without the express permission from Elsevier.] 


\section{Methods}

\subsection{Experiment 1: stimulus development and behavioral pilot study}

The goal of this behavioral study was to identify a set of famous name stimuli that distinctly represented persons who achieved their fame in the 1990s (90s) or 1950s (50s) time periods that could be used in a subsequent fMRI study. An initial corpus of 274 people's names (first and last) comprised of both famous and non-famous individuals were compiled. The famous names consisted of well-known entertainers, politicians, criminals, or sports figures obtained through magazines, trivia books, and the Internet. Unfamiliar names were selected randomly from a local phone book to serve as foils (FO).

The stimulus set was piloted on 24 young $(M=9 / F=15$; mean age $=26.78$ years, S.D. $=3.22)$ and 24 older $(M=11 / F=13$; mean age $=68.05$ year, S.D. $=6.80$ ) healthy adults. Subjects completed a written questionnaire that asked participants to provide the following information: (1) is this person famous? (2) for what is the person famous? (3) is the person dead or alive? (4) what is the occupation of this person (choose from 10 occupations listed)? and (5) how often have you heard about this person in the last year (ranging from 0 [never] to 4 [several times a month or more])?

For the final stimulus set to be used in the imaging protocol, names were chosen from the pilot study based on the following guidelines: (1) a name included in the 90 s condition yielded greater than $90 \%$ recognition accuracy for both the younger and older age subject groups, (2) a famous name selected for the 50 s condition was recognized by greater than $90 \%$ of the older adults but less than $30 \%$ of the young adults. This maximized the likelihood that these stimuli were famous, but had become sufficiently obscure during the contemporary period since they were not recognized by most of the younger subjects. (3) Non-famous name foils were selected if correctly rejected by $90 \%$ of both the young and older subjects. In this manner,

[Neuropsychologia, Vol 43, No. 5 (2005): pg. 693-703. DOI. This article is (C Elsevier and permission has been granted for this version to appear in e-Publications@Marquette. Elsevier does not grant permission for this article to be further copied/distributed or hosted elsewhere without the express permission from Elsevier.] 
a final stimulus set consisting of 90 names: 30 50s, 30 90s, and $30 \mathrm{FO}$ were selected (see Appendix A). Male and female names were equally represented in both the famous and non-famous name sets.

Percent correct recognition for the final set of 90 famous and non-famous names for young and older pilot subjects is shown in Fig. 1. As intended based on the selection criteria, younger subjects performed significantly worse at identifying 50 s names than older subjects, $[\mathrm{t}(32.7)=15.5, \mathrm{p}<.001]$. In contrast, there was no difference between groups in recognition accuracy for the famous names from the $90 \mathrm{~s},[\mathrm{t}(45)=1.40, \mathrm{p}<.17$ ] or correct rejection of non-famous name foils, $[\mathrm{t}(40)=.68, \mathrm{p}<.50]$. Table 1 summarizes the extent of semantic knowledge that the older subjects reported for the $50 \mathrm{~s}$ and $90 \mathrm{~s}$ stimuli. No significant differences between the two stimulus classes were observed on a three-point rating of semantic knowledge ( $1=1$ recognize the name, but nothing else, $2=1$ recognize the name and know their occupation but nothing else, $3=1$ know additional specific details about this person). The occupational category was more likely to be correctly identified for the 50 s than $90 \mathrm{~s}$ stimuli $(p<.01)$. As expected for famous individuals who have not been in the public domain for 40 years, older subjects were less accurate in noting whether the famous person was dead or alive for 50 s than 90 s individuals $(p<.001)$. Likewise, the frequency of exposure during the past year was significantly less for the 50 s than 90 s names $(p<.001)$.

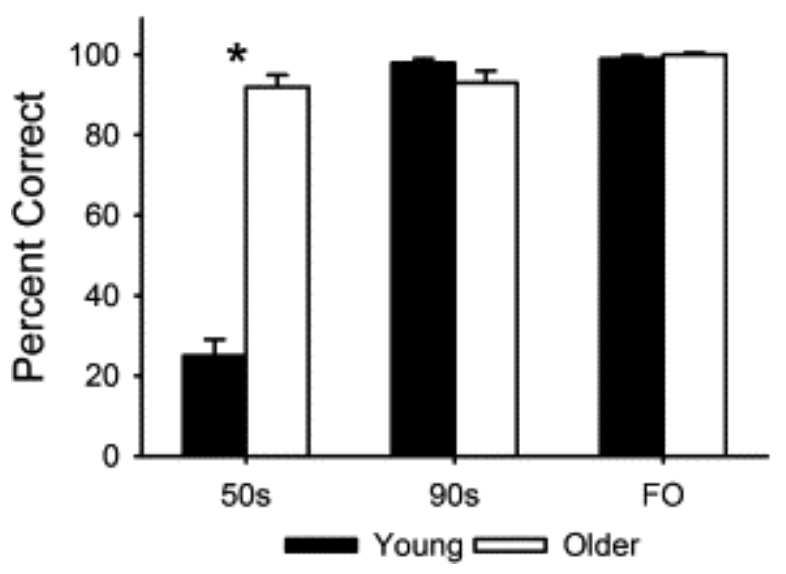

Fig. 1. Percent correct identification of famous names from two epochs (50s and 90s) and percent correct rejection of foils for young and older participants. Note that

[Neuropsychologia, Vol 43, No. 5 (2005): pg. 693-703. DOI. This article is (C Elsevier and permission has been granted for this version to appear in e-Publications@Marquette. Elsevier does not grant permission for this article to be further copied/distributed or hosted elsewhere without the express permission from Elsevier.] 
NOT THE PUBLISHED VERSION; this is the author's final, peer-reviewed manuscript. The published version may be accessed by following the link in the citation at the bottom of the page.

younger subjects performed poorly on recognition of famous 50 s names

demonstrating that these individuals have not been recently exposed in the media.

Table 1. Mean (S.D.) of semantic knowledge variables of 1990s and 1950s famous name stimuli

\section{Variable}

Average semantic knowledge 3-point scale (23)

Occupation category percent correct (21)

Dead or alive percent correct (24)

Average frequency of exposure times during previous year (22) $2.69(.70) .79(.70)^{* *}$

-Data obtained from older subjects $(n=24)$ in stimulus development pilot study.

a Number of participants included in analyses.

$* p<.01$.

$* * p<.001$.

\section{0s 50s}

$1.30(.27) 1.23(.31)$

$82(7) \quad 89(6)^{*}$

$89(12) \quad 65(13)^{* *}$

\subsection{Experiment 2: fMRI study of famous name recognition}

\subsubsection{Participants}

Fifteen healthy, right-handed older subjects ( 11 females; mean age $=70.4$ years, range $=60-79$ years) participated in the $\mathrm{fMRI}$ experiment. None participated in Experiment 1. Subjects were strongly right-handed (mean laterality quotient $=92.7$, range $=84-100$ ) on the Edinburgh handedness inventory (Oldfield, 1971). Subjects were excluded if they reported a history of neurological disease, major psychiatric disturbance, or substance abuse, or were taking psychoactive prescriptive medications. A cognitive screening examination preceded the scan session. All subjects performed within normal limits on the mini-mental state examination (Folstein, Folstein, $\&$ McHugh, 1975) [ mean $=29.2$, range $=27-30$, standard deviation $=.97$ ] and the repeatable battery for assessment of neuropsychological status (Randolph, 1998; Randolph, Tierney, Mohr, $\&$ Chase, 1998) $[$ mean $=105.1$, range $=95-129$, standard deviation $=12.1 \mathrm{]}$. Informed consent was obtained from subjects according to the institutional guidelines established by the Medical College of Wisconsin Human Subjects Review Committee. Subjects were compensated for their time.

[Neuropsychologia, Vol 43, No. 5 (2005): pg. 693-703. DOI. This article is (C) Elsevier and permission has been granted for this version to appear in e-Publications@Marquette. Elsevier does not grant permission for this article to be further copied/distributed or hosted elsewhere without the express permission from Elsevier.] 


\subsubsection{I maging task}

Name stimuli from the three conditions were presented visually in random order ( $4 \mathrm{~s}$ per stimulus). Inactive periods ( $4 \mathrm{~s})$, consisting of a single centrally-placed fixation crosshair, were randomly interspersed in the ratio of 2:1 (name: fixation trials). Participants were instructed to make a right index finger key press if the name was famous and the right middle finger if the name was unfamiliar. Stimuli were presented in three imaging runs of 30 trials each ( 10 stimuli from each of the three name conditions, 15 fixation trials). Twelve seconds of fixation were added to both the beginning and the end of each run. Run order was counterbalanced across subjects.

\subsubsection{Functional MRI}

Whole-brain, event-related functional MRI was conducted on a commercial 1.5 T scanner (Sigma; General Electric Medical Systems, Milwaukee, WI) equipped with a three-axis local gradient head coil and an elliptical endcapped quadrature radiofrequency coil (Medical Advances, Milwaukee, WI). Echoplanar images were collected using a single-shot, blipped, gradient-echo echoplanar pulse sequence [echo time (TE), $40 \mathrm{~ms}$; field of view (FOV), $24 \mathrm{~cm}$; matrix size, $64 \times 64]$. For the three imaging runs, 22 contiguous sagittal $6-\mathrm{mm}$ thick slices were selected to provide coverage of the entire brain (voxel size $=3.75 \mathrm{~mm} \times 3.75 \mathrm{~mm} \times 6 \mathrm{~mm}$ ). The interscan interval [repetition time (TR)] was $2 \mathrm{~s}$. During each imaging series, 132 sequential echoplanar images were collected. At the beginning of the scan session, high-resolution, three-dimensional spoiled gradientrecalled at steady-state (SPGR) anatomic images were acquired [TE $=5 \mathrm{~ms} ; \mathrm{TR}=24 \mathrm{~ms} ; 40^{\circ}$ flip angle; number of excitations $(\mathrm{NEX})=1$; slice thickness $=1.2 \mathrm{~mm}$; FOV $=24 \mathrm{~cm}$; resolution $=256 \times 192$ ]. Foam padding was used to reduce head movement within the coil.

Functional images were generated using the Analysis of Functional Neurol mages (AFNI) software (Cox, 1996). Each image time series was spatially registered in-plane to reduce the effects of head motion using an iterative linear least squares method. A

[Neuropsychologia, Vol 43, No. 5 (2005): pg. 693-703. DOI. This article is (C) Elsevier and permission has been granted for this version to appear in e-Publications@Marquette. Elsevier does not grant permission for this article to be further copied/distributed or hosted elsewhere without the express permission from Elsevier.] 
deconvolution analysis was used to extract a hemodynamic response (impulse response function; IRF) for each of the three types of name stimuli from the time-series. In addition, only correct responses (true positives for famous names and true rejections for unfamiliar names) were incorporated into the estimate of the IRF for each stimulus type. IRFs were modeled for the 2-14 s period post stimulus onset. Individual anatomical and functional scans were linearly interpolated to $1 \mathrm{~mm}^{3}$ voxels, co-registered, and transformed into standard stereotaxic space (Talairach \& Tournoux, 1988). To compensate for normal variation in anatomy across subjects, functional images were blurred using a $4 \mathrm{~mm}$ Gaussian full-width half-maximum filter.

\subsubsection{Voxel-wise analysis}

The dependent variable consisted of the area under the curve (AUC) of the IRF at 4, 6, and 8 s post stimulus onset. A one-way repeated measures analysis of variance (ANOVA) was applied to the three conditions on a voxel-wise basis across the 15 subjects followed by a pooled variance t-test to compare each of the conditions in a pairwise manner (90s versus FO, 50s versus $F O, 50$ s versus $90 \mathrm{~s}$ ). A statistical threshold was applied to the data $[\mathrm{t}(14)=2.960, \mathrm{p}<.005]$. A minimum cluster size threshold of .20 ml was applied as an additional procedure for minimizing false positive activation foci from the brain maps (Forman et al., 1995). Only activation within the MTL is reported.

\subsubsection{Region of interest (ROI) analysis}

This analysis was performed to examine the averaged IRFs generated from activated clusters located within four anatomical ROIs: right and left hippocampus and right and left PHG. Clusters were defined as "activated" if a significant difference was observed on any of the voxel-wise subtractions of the three stimulus conditions (90s versus FO, 50s versus FO, or 50s versus 90s). Repeated measures ANOVA and planned comparisons were used to compare the AUC of the averaged IRFs for the 90s, 50s, and FO stimuli. Anatomical ROIs were defined by manually tracing each subject's hippocampus and PHG using the gyrus finder plug-in of AFNI (Cox, 1996).

[Neuropsychologia, Vol 43, No. 5 (2005): pg. 693-703. DOI. This article is (C) Elsevier and permission has been granted for this version to appear in e-Publications@Marquette. Elsevier does not grant permission for this article to be further copied/distributed or hosted elsewhere without the express permission from Elsevier.] 
For the hippocampus, the anterior and posterior boundaries were identified in the sagittal plane, with the lateral ventricles serving as the boundaries. The posterior boundary was marked by the last coronal slice where the hippocampus was present. The anterior boundary, which marks the division between the hippocampus and the amygdala, was located by visualizing a sagittal slice where the temporal horn of the lateral ventricle makes a $90^{\circ}$ bend around the hippocampus. On the most posterior coronal slices, the lateral boundary was defined by the crus of the fornix. In the anterior slices, the lateral boundary was defined by the temporal horn of the lateral ventricle. Care was taken so as to exclude the tail of the caudate nucleus. In posterior slices, the medial boundary was marked by the splitting of the hippocampus and pulvinar. In the remaining slices, the medial boundary was defined by the CSF in the uncal cistern. On the more anterior slices, the dorsal boundary was defined by the presence of the alveus, which appears as a thin white line dividing the superior portion of the hippocampus from the overlapping amygdala. When the alveus was not clearly seen, an imaginary horizontal line was drawn from the superior most portion of the temporal horn of the lateral ventricle to the gyrus ambiens to serve as the dorsal boundary. The inferior boundary of the hippocampus was marked by the white matter inferior to the hippocampus. These criteria were developed by Sabsevitz and Binder (unpublished work).

The boundaries of the PHG were adapted from Kim et al. (2000). The posterior boundary was marked by the disappearance of the splenium and the presence of the isthmus between the collateral and anterior calcarine sulcus. The anterior boundary was set at the image where the uncus was present. The cerebral spinal fluid of the uncal cistern served as the medial boundary and the lateral boundary was set as an imaginary line at a $45^{\circ}$ angle serving as an extension of the collateral sulcus between the PHG and fusiform gyrus.

Fig. 3A depicts a typical tracing of the hippocampus and PHG based on the above criteria.

\section{Results}

\subsection{Behavioral data (Exp. 2)}

[Neuropsychologia, Vol 43, No. 5 (2005): pg. 693-703. DOI. This article is (C Elsevier and permission has been granted for this version to appear in e-Publications@Marquette. Elsevier does not grant permission for this article to be further copied/distributed or hosted elsewhere without the express permission from Elsevier.] 
Accuracy and reaction times (correct trials only) are presented in Table 2. No significant differences were observed in accuracy as a function of stimulus type. The main effect for reaction time was significant $(F(2,28)=12.90, p<.001)$. Planned comparisons revealed significant differences between the 50 s and FO stimuli $(F(1,14)=16.46, p<.001)$ and between the 90 s and $F O$ stimuli $(F(1,14)=11.45, p<.004)$. No significant differences were observed between 90 s and 50 s stimuli.

Table 2. Accuracy and reaction time for older subjects in fMRI study

Mean

92.80

90.33

94.60

FO

1317.13

1241.67

1540.13

Reaction time

90s

$50 \mathrm{~s}$
S.D.

\subsection{Voxel-wise analysis (Exp. 2)}

Significantly activated voxels within the MTL regions are reported in Table 3 and Fig. 2. A post-hoc comparison subtracting the FO from the 90 s condition resulted in significant clusters of activation in the right hippocampus and bilateral PHG. Subtracting FO from the 50 s condition resulted in significant clusters of activation in the left hippocampus and right PHG. No clusters were observed in which the FO demonstrated greater activation than the famous names from either era. The overall volume of activation was greater for the $90 \mathrm{~s}$ minus FO subtraction than for the 50 s minus FO subtraction (Table 3); however, a voxel-wise subtraction of the 90 s from 50 s conditions, and vice versa, resulted in no significant areas of activation within the MTL. This apparent discrepancy was further explored using an ROI analysis of averaged IRFs.

Table 3. Significant areas of increased MR signal intensity $(p<.005)$ derived from subtraction of foils (FO) from famous name conditions (50s, 90s) in hippocampus and PHG (see also Fig. 1)

[Neuropsychologia, Vol 43, No. 5 (2005): pg. 693-703. DOI. This article is (C) Elsevier and permission has been granted for this version to appear in e-Publications@Marquette. Elsevier does not grant permission for this article to be further copied/distributed or hosted elsewhere without the express permission from Elsevier.] 
NOT THE PUBLISHED VERSION; this is the author's final, peer-reviewed manuscript. The published version may be accessed by following the link in the citation at the bottom of the page.

\section{Region}

Hippocampus

$90 \mathrm{~s}>\mathrm{FO}$

$50 \mathrm{~s}>\mathrm{FO}$
Left

$\mathbf{x}$

$$
\text { y }
$$

z

Vol.

Right

$\mathbf{z}$

Vol.

Parahippocampal gyrus

$\begin{array}{lllllllll}90 \mathrm{~s}>\text { FO } & -11 & -42 & 4 & 659 & 16 & -47 & 1 & 1123 \\ & -31 & -32 & 12 & 442 & & & & \\ \text { 50s > FO } & & & & & 12 & -45 & 5 & 276\end{array}$

Vol., volume in microliters.

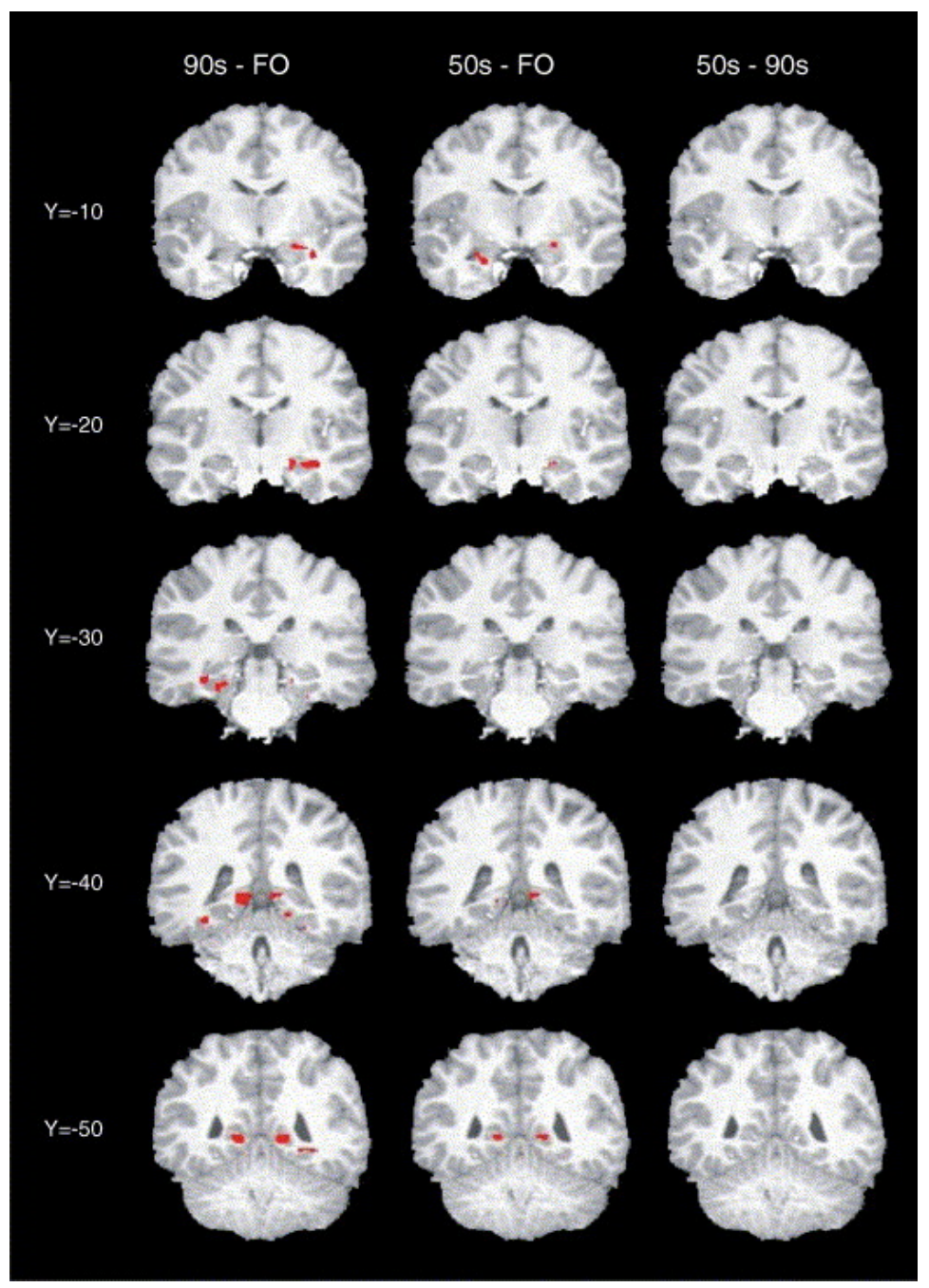

Fig. 2. Voxel-wise activation maps showing regions of increased MR signal intensity within the medial temporal lobe. Left side of brain is on the reader's left.

[Neuropsychologia, Vol 43, No. 5 (2005): pg. 693-703. DOI. This article is (C Elsevier and permission has been granted for this version to appear in e-Publications@Marquette. Elsevier does not grant permission for this article to be further copied/distributed or hosted elsewhere without the express permission from Elsevier.] 
NOT THE PUBLISHED VERSION; this is the author's final, peer-reviewed manuscript. The published version may be accessed by following the link in the citation at the bottom of the page.

\subsection{ROI analysis (Exp. 2)}

Fig. 3B presents the averaged IRFs for activated regions within the right and left hippocampus and PHG for the 50s, 90s, and FO conditions. Table 4 summarizes the results of the AUC analysis (4- $8 \mathrm{~s}$ post-stimulus) for the right and left hippocampus and PHG. For the left hippocampus and PHG, 90s and 50s stimuli demonstrated increased activation relative to $\mathrm{FO}$, but did not differ from each other. In contrast, for the right hippocampus and PHG, 90s and 50s stimuli not only demonstrated increased activation relative to $\mathrm{FO}$, but the $90 \mathrm{~s}$ stimuli demonstrated greater activation relative to 50 s stimuli.

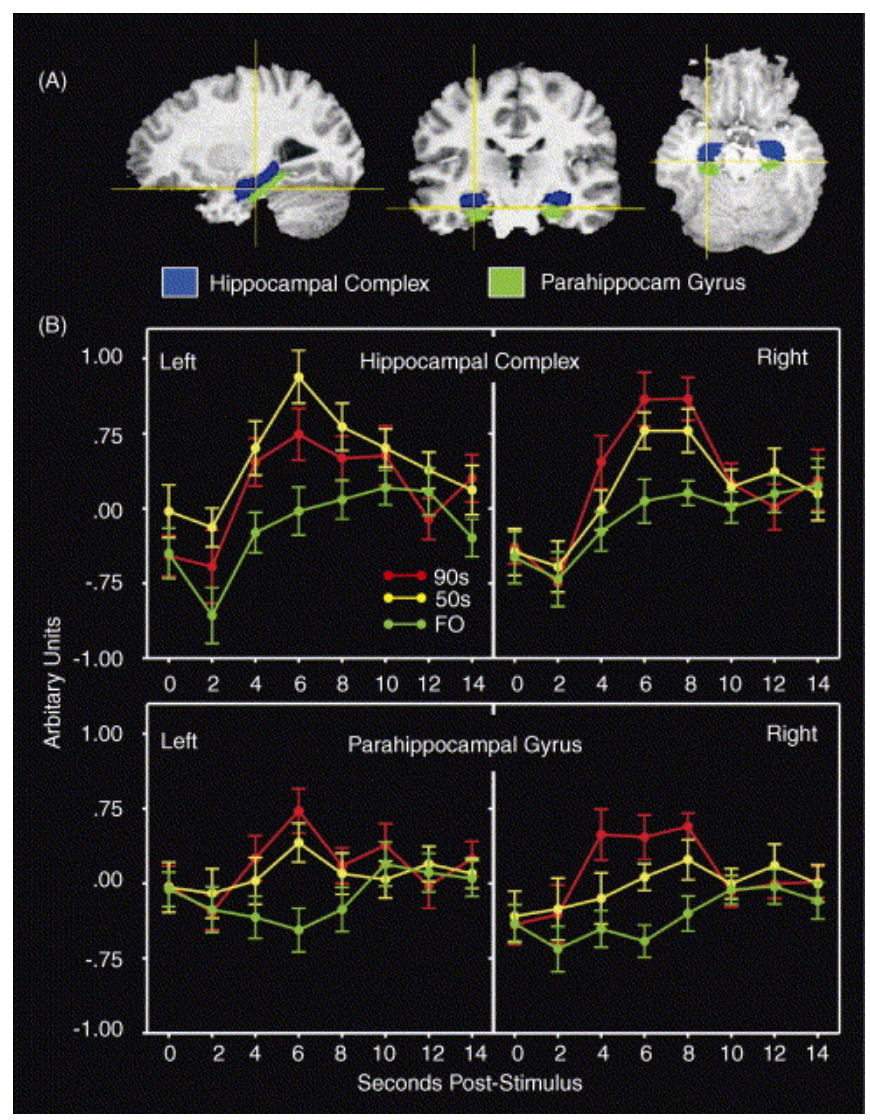

Fig. 3. (A) Areas defining the anatomical masks for the hippocampus and parahippocampal gyrus for a typical subject. (B) Plots of the hemodynamic response functions for each condition (50s, 90s, and FO) and ROI (hippocampus, PHG).

[Neuropsychologia, Vol 43, No. 5 (2005): pg. 693-703. DOI. This article is (C Elsevier and permission has been granted for this version to appear in e-Publications@Marquette. Elsevier does not grant permission for this article to be further copied/distributed or hosted elsewhere without the express permission from Elsevier.] 
NOT THE PUBLISHED VERSION; this is the author's final, peer-reviewed manuscript. The published version may be accessed by following the link in the citation at the bottom of the page.

Table 4. Results of repeated measures ANOVA for ROI analyses

\begin{tabular}{lccccccc} 
& \multicolumn{4}{c}{ Left } & \multicolumn{2}{c}{ Right } \\
& Diff & \multicolumn{1}{c}{ S.E. } & p-Value & Diff & S.E. & p-Value \\
Hippocampus & & & & & & \\
90s vs. FO & .419 & .094 & $\mathbf{. 0 0 2}$ & .590 & .101 & $<.001$ \\
50s vs. FO & .649 & .161 & $\mathbf{. 0 0 4}$ & .343 & .086 & $\mathbf{. 0 0 4}$ \\
90s vs. 50s & .229 & .133 & NS & .247 & .090 & $\mathbf{. 0 4 7}$ \\
Parahippocampal gyrus & & & & & \\
90s vs. FO & .494 & .106 & $<.001$ & .635 & .123 & $<.001$ \\
50s vs. FO & .355 & .123 & $\mathbf{. 0 3 7}$ & .330 & .096 & $\mathbf{. 0 1 2}$ \\
90s vs. 50s & .138 & .125 & NS & .305 & .088 & $\mathbf{. 0 1 2}$
\end{tabular}

-Diff, mean difference between conditions; S.E., standard error of the mean; $p$-values with significant differences shown in bold print; and NS, not significant.

\section{Discussion}

The current study employed an event-related fMRI design to contrast the MR signal intensity changes in the MTL region in the recognition of famous names from recent and remote time periods (1990s versus 1950s). Results indicated increased activity bilaterally in the hippocampus and PHG during the recognition of familiar names from both time periods when compared to non-famous names. However, the impulse response functions in the right hippocampal complex and right PHG demonstrated a differential response to stimuli from different time epochs. That is, the 1990s stimuli demonstrated a significantly greater area-under-the-curve than the 1950 s stimuli. This difference across time epochs was not seen in the left hippocampus or left PHG. These findings have relevance for current proposals concerning the role of the MTL region in long-term memory retrieval as well as for recent discussions concerning the neural basis for person recognition and identification processes.

Consideration of the role of MTL during retrieval of recent and remote memories is germane, as different neural systems and cognitive operations may contribute to the retrieval of autobiographical episodic events and public semantic remote memory information (Viskontas, McAndrews, \& Moscovitch, 2002). Increased MTL activity has been previously reported for the recognition of and identification of well-known faces (Kapur et al., 1995; Leveroni et al., 2000; Sergent et al., 1992) and the current study extends this finding to famous names

[Neuropsychologia, Vol 43, No. 5 (2005): pg. 693-703. DOI. This article is (C) Elsevier and permission has been granted for this version to appear in e-Publications@Marquette. Elsevier does not grant permission for this article to be further copied/distributed or hosted elsewhere without the express permission from Elsevier.] 
as well. However, these previous studies did not systematically examine the influence of a temporal gradient on the presence and extent of MTL activity. This issue is of critical relevance for the current debate concerning the role of the MTL region in the time course of memory retrieval processes.

\subsection{MTL activity for recognizing famous names}

The role of the MTL region in retrieval of long-term memory has become the focus of considerable discussion, and recent functional neuroimaging studies have been designed to provide data relevant to this issue. The core issue revolves around the time course for MTL involvement in retrieval of information from long-term memory. The limited functional neuroimaging data relevant to this question have produced mixed results, and it is becoming increasingly apparent that a number of important factors including type of information (e.g., episodic or semantic), stimulus characteristics (e.g., emotional valence), and individual subject differences related to autobiographical significance (e.g., extent of knowledge or type of personal experiences subjects have with respect to the stimuli) could impact the nature and extent of MTL involvement in retrieval.

Our findings revealed that both recent and remote famous names produced significant activation bilaterally in the hippocampus and the PHG, relative to foils. However, we also observed a temporal gradient of activity in the right hippocampus and right PHG, with 1990s stimuli showing a greater area-under-the-curve than more remote 1950s stimuli, which in turn showed a greater area-under-thecurve than foils. No such temporal gradient was observed for the left hippocampus or left PHG. If identification of the names of famous persons reflected primarily semantic memory retrieval, then a temporal gradient would have been predicted by both models, with MTL activity decreasing in proportion to the remoteness of the memory. However, our observations that even remote memories produced significant activity in the MTL bilaterally and that a temporal gradient was observed in the right MTL only, suggests that memories for famous names may not have a purely semantic component. Instead, a growing body of evidence suggests that memories for famous names have a significant autobiographical, episodic component

[Neuropsychologia, Vol 43, No. 5 (2005): pg. 693-703. DOI. This article is (C Elsevier and permission has been granted for this version to appear in e-Publications@Marquette. Elsevier does not grant permission for this article to be further copied/distributed or hosted elsewhere without the express permission from Elsevier.] 
(Westmacott, Black, Freedman, \& Moscovitch, 2004; Westmacott \& Moscovitch, 2003). The degree of autobiographical significance attributable to names of famous persons by our subjects may account for the pattern of activation we observed, with significant MTL activity being observed bilaterally even for remotely famous names.

Maguire and Frith (2003) reported a similar pattern of findings with respect to the retrieval of autobiographical events. Bilateral hippocampal activity was observed during retrieval of both recent and remote autobiographical events. However, the right hippocampus demonstrated greater activity in response to recent as compared to remote autobiographical memories. This temporal gradient of activity during retrieval of recent and remote autobiographical events was not observed for the left hippocampus. Bilateral hippocampal activity also was observed during retrieval of autobiographical as opposed to public events. In addition, our findings agree with Haist et al.'s (2001) increased activation in right entorhinal cortex but differ with respect to the more modest activation in the right hippocampus associated with 1990s relative to remote stimuli in that study. It is possible that our use of an event-related design and a larger number of subjects permitted us to detect significant, temporally-graded activation in the right hippocampal complex. Finally, Ryan et al. (2001) reported bilateral hippocampal activity during retrieval of both recent and remote autobiographical events that was not present during rest or during a sentence completion task, which is consistent with our findings. While not specifically discussed in the article, the impulse response function they presented for the right hippocampus appeared to be greater in response to recent relative to remote autobiographical events, suggesting the possibility of a right hippocampal temporal gradient consonant with that reported by Maguire and Frith (2003), as well as in our study. Considering our results and the findings of these previous studies, it is possible that a broader region of right MTL (hippocampus and PHG) may be differentially responsive to the remoteness of autobiographically relevant material.

Evidence supporting the influence of autobiographical significance on the organization and representation of semantic memory, particularly with respect to famous names, has been demonstrated by (Westmacott et al., 2004; Westmacott \& Moscovitch, 2003). In their initial study (Westmacott et al., 2003), subjects

[Neuropsychologia, Vol 43, No. 5 (2005): pg. 693-703. DOI. This article is (C Elsevier and permission has been granted for this version to appear in e-Publications@Marquette. Elsevier does not grant permission for this article to be further copied/distributed or hosted elsewhere without the express permission from Elsevier.] 
demonstrated a performance advantage for famous names with high autobiographical significance relative to those with low autobiographical significance. Autobiographical experience with names of famous individuals was shown to affect the way in which these semantic concepts were represented, supporting the interdependence between episodic and semantic memories. That is, in addition to general semantic knowledge about famous persons that may be common across most people, the autobiographical significance of famous persons may also produce a unique memorial representation specific to each individual. In a subsequent study (Westmacott et al., 2004), patients with semantic dementia demonstrated a performance advantage for autobiographically significant episodes associated with famous persons relative to patients with MTL amnesia and Alzheimer's disease, providing evidence that memories associated with autobiographically significant famous persons depend upon MTL structures. Our finding of significant bilateral MTL activation in response to recognition of both recent and remote famous names is consistent with this interpretation.

If recognition of famous names were considered to have a substantial autobiographical, episodic component, our findings that both recent and remote famous names produced significant activation bilaterally in the left hippocampus and the left PHG, relative to foils, would support predictions made by the MTT model. That is, the hippocampus and PHG demonstrate significant activity in response to famous names, regardless of the age of the memory. This pattern of results would not be as consistent with predictions based on the $\mathrm{HC}$ model, although it is possible that an argument could be made that despite the observation of hippocampal activation associated with remote stimuli, it may not contribute to performance. Additionally, unlike the findings in the Haist et al. (2001) study, we did not find a significant difference in the activity of either the hippocampus or PHG for recent or remote famous names when compared to unfamiliar names. Rather, both regions demonstrated a significant increase in activity for both the recent and remote time periods. These findings would appear to indicate an increase in MTL activity irrespective of the age of the memory, consistent with MTT (Nadel \& Moscovitch, 1997).

There are several important methodological differences between the current and Haist studies. Perhaps most noteworthy is our use of

[Neuropsychologia, Vol 43, No. 5 (2005): pg. 693-703. DOI. This article is (C Elsevier and permission has been granted for this version to appear in e-Publications@Marquette. Elsevier does not grant permission for this article to be further copied/distributed or hosted elsewhere without the express permission from Elsevier.] 
an event-related design, which permits the construction of activation maps that are only made up of correct name familiarity trials. In addition, our stimulus development efforts (Study 1) assured an equivalence of the stimuli on the dimensions of familiarity and extent of semantic knowledge. Behavioral data collected during the scanning session confirms that these objectives were met. First, name recognition accuracy rates were above $90 \%$ for stimuli from both the 1950 s and the 1990s. Second, average self-report rating of semantic knowledge obtained during the pilot study was similar for the two time periods (Table 1). As might be expected, frequency of exposure to the name and knowledge of whether the famous person was alive or dead were significantly different for the two periods, validating the fact that semantic knowledge about individuals famous during the 50 s was not being updated.

Recently and remotely famous names demonstrated greater activation relative to foils in the right hippocampal complex and right PHG, which would also be consistent with MTT, although the differential response of the right hippocampus and right PHG to recently and remotely famous names would not have been predicted on the basis of the MTT model. The observed temporal gradient of activation would be consistent with the $\mathrm{HC}$ model in the right MTL. Similar asymmetries in patterns of MTL activation have been observed in previous studies (Maguire \& Frith, 2003; Ryan et al., 2001). What factors could possibly be associated with the observed right MTL temporal gradient? One possibility is that both recent and remote famous names may be associated with a visual image of the individual; as memories become more remote, the visuoperceptual representation of the person-image may decline or may become less salient over time (cf., Pigott \& Milner, 1993), perhaps because it is not as regularly updated as recent memories. A second possibility is that emotional valence or intensity associated with a famous name may decline or degrade over time, again contributing to a weaker representation than recent stimuli that may be updated more frequently. In a PET activation study, Fink et al. (1996) suggested that right hemisphere structures may be preferentially activated during recall of affect-laden, personally relevant, autobiographical memories, although remoteness of memories was not varied systematically in this study. However, Westmacott and Moscovitch (2003) demonstrated that autobiographical significance of famous names interacts strongly

[Neuropsychologia, Vol 43, No. 5 (2005): pg. 693-703. DOI. This article is (C) Elsevier and permission has been granted for this version to appear in e-Publications@Marquette. Elsevier does not grant permission for this article to be further copied/distributed or hosted elsewhere without the express permission from Elsevier.] 
with their emotionality and vividness, raising the possibility that factors related to emotional valence and/or intensity may underlie the differential response of right hemisphere MTL structures to remoteness of memories. Regardless of the underlying mechanism, the observed right MTL temporal gradient supports the $\mathrm{HC}$ model, while the greater activation of both recent and remote stimuli, as compared with foils, would also be consistent with the MTT model. Thus, partial support of both models was observed in the right MTL.

\subsection{Person identity network}

The current findings also have relevance for the broader topic of characterizing the neural systems underlying familiar person identification. Recent discussion has revolved around the question of whether person identification includes a more extensive bilateral neural network than is commonly evident for general object semantic memory processes (Hodges, Bozeat, Lambon Ralph, Patterson, \& Spatt, 2000). We found that recognition of famous names produced both left and right-sided MTL activity. Previous findings from clinical lesion studies and functional neuroimaging investigations have implicated a bilateral temporal lobe network, including the hippocampal complex, in the recognition and identification of famous faces. Patients with either right or left-sided unilateral temporal lobe epilepsy are impaired at providing semantic details and names of famous faces (Seidenberg et al., 2002; Viskontas et al., 2002). A recent fMRI study also revealed bilateral hippocampal activity for recognition of familiar faces contrasted with unfamiliar faces (Leveroni et al., 2000). The involvement of right temporal lobe systems in the processing of familiar faces is not unexpected; however, the current findings indicate right and left sided MTL activity when familiar names are used as the stimulus input as well. These findings are consistent with the viewpoint of a distributed bilateral neural network including the medial temporal lobes in the retrieval from the person identity network. In addition, the current study focused its examination on the MTL region, and it undoubtedly represents only one part of a more extensive neural network (e.g., frontal cortex, lateral temporal lobe, posterior cingulate) that is critical for the retrieval of person identity information (Gorno Tempini et al., 1998; Leveroni et al., 2000; Maddock, Garrett, \& Buonocore, 2001; Shah et al., 2001).

[Neuropsychologia, Vol 43, No. 5 (2005): pg. 693-703. DOI. This article is (C Elsevier and permission has been granted for this version to appear in e-Publications@Marquette. Elsevier does not grant permission for this article to be further copied/distributed or hosted elsewhere without the express permission from Elsevier.] 
Considerable research is still needed to articulate the contribution and role of these various neural regions in the operation of the person identity system.

\subsection{Summary and conclusions}

Because knowledge of familiar individuals may be acquired during different periods in an individual's life, the study of person identity provides a unique opportunity to investigate the timedependent course of MTL involvement in retrieval from long-term memory. Results of experimental animal studies and human lesion studies (Squire \& Alvarez, 1995) have led to the viewpoint that the hippocampal complex plays a time limited role in long-term memory retrieval processes (hippocampal consolidation model). More recently, an alternative viewpoint (Nadel \& Moscovitch, 1997) was proffered in which the hippocampal complex acts to update and enrich the memory as long as it exists (multiple trace theory model). We present data from an event-related fMRI study of 15 elderly subjects contrasting recognition of famous names from a recent and remote time epoch with unfamiliar names. Overall, the findings of this study provide apparent support for both models. Increased bilateral MTL activity was evident for both recent and remote famous names, relative to foils, consistent with the MTT model. However, a temporal gradient was observed in the right hippocampus and right PHG, with recent famous names producing significantly greater MTL activation relative to remotely famous names, consistent with the $\mathrm{HC}$ model. The right hemisphere findings with famous names in this study are consistent with and extend previous findings from Haist et al. (2001), who used famous faces as stimuli, suggesting modest support for the HC model within the hippocampal complex proper, although stronger support is observed within the PHG. The left hemisphere findings provide compelling evidence in favor of MTT.

\section{Acknowledgements}

This study was supported by grants from the National Institutes of Health (R01 AG022304, P01 MH51358) to S.M.R., the Medical College of Wisconsin General Clinical Research Center (M01 RR00058), and the W.M. Keck Foundation. We would like to thank Jill Dorflinger, Sally Durgerian, Cathy Elsinger, and Amanda Moths for their assistance.

[Neuropsychologia, Vol 43, No. 5 (2005): pg. 693-703. DOI. This article is (C Elsevier and permission has been granted for this version to appear in e-Publications@Marquette. Elsevier does not grant permission for this article to be further copied/distributed or hosted elsewhere without the express permission from Elsevier.] 


\section{Appendix A.}

1950s

Eddie Fisher

Bobby Vinton

Stan Musial

Troy Donahue

Ben Hogan

Vic Damone

Gina Lollobrigida

David Niven

Jack Carter

Paul Hornung

David Frost

Rex Harrison

William Proxmire

Warren Spahn

Johnny Weissmuller

Mamie Van Doren

Walter Brennan

Pat Paulsen

Kate Smith

Leo Durocher

Pier Angeli

Arthur Godfrey

Tab Hunter

E. G. Robinson

Mike Todd

Mitch Miller

Jo Stafford

Phil Silvers

Al Hirt

J ohn Cameron Swayze 1990s

Paula J ones

Clarence Thomas

George Clooney

Ken Starr

J on-Benet Ramsey

Alan Greenspan

Elian Gonzales

Katie Couric

Brett Favre

Hugh Grant

Celine Dion

Colin Powell

Jack Kevorkian

Brad Pitt

Linda Tripp

Newt Gingrich

Martha Stewart

Boris Yeltsin

Madeline Albright

Leonardo DiCaprio

Jerry Seinfeld

Johnny Cochran

Norman Schwarzkopf J eremy Trombetta

Monica Lewinski

J anet Reno

Rush Limbaugh

Tiger Woods

Garth Brooks

Chelsea Clinton

H. Ross Perot
Foils

Ellen Patterson

Howard Feinberg

Simon Harrison

David Schmidt

Gilbert Locke

Benjamin Lackey

William J ohannsen

Barbara Pabst

Betty Paeske

Edward Gurgul

Donald Cunningham

James Wilson

Bill Duncan

Melissa Appel

Henry Glueckenstein

Sharon Quinnett

Lillian Uzel

J ames Turkington

Donna Ottens

Tora Smith

Alfred Wessely

Craig Case

Michelle Cross

Keith Rowden

Cora Bester

Matthew Kregel

Karen I ves

Wayne Wheeler

Alan Polette

[Neuropsychologia, Vol 43, No. 5 (2005): pg. 693-703. DOI. This article is (C) Elsevier and permission has been granted for this version to appear in e-Publications@Marquette. Elsevier does not grant permission for this article to be further copied/distributed or hosted elsewhere without the express permission from Elsevier.] 
NOT THE PUBLISHED VERSION; this is the author's final, peer-reviewed manuscript. The published version may be accessed by following the link in the citation at the bottom of the page.

\section{References}

Bruce and Young, 1986

V. Bruce, A. Young. Understanding face recognition. British Journal of Psychology, 77 (1986), pp. 305-327

Cabeza and Nyberg, 1997

R. Cabeza, L. Nyberg. Imaging cognition: an empirical review of PET studies with normal subjects. Journal of Cognitive Neuroscience, 9 (1997), pp. 1-26

Cox, 1996

R.W. Cox. AFNI: software for analysis and visualization of functional magnetic resonance neuroimages. Computers and Biomedical Research, 29 (1996), pp. 162-173

Fink et al., 1996

G.R. Fink, H.J . Markowitsch, M. Reinkemeier, T. Bruckbauer, J.

Kessler, W.D. Heiss. Cerebral representation of one's own past: neural networks involved in autobiographical memory. Journal of

Neuroscience, 16 (1996), pp. 4275-4282

Folstein et al., 1975

M.F. Folstein, S.E. Folstein, P.R. McHugh. Mini-mental state: a practical method for grading the cognitive state of patients for the clinician.

Journal of Psychiatric Research, 12 (1975), pp. 189-198

Forman et al., 1995

S.D. Forman, J.D. Cohen, M. Fitzgerald, W.F. Eddy, M.A. Mintun, D.C.

Noll. Improved assessment of significant activation in functional magnetic resonance imaging ( $\mathrm{fMRI}$ ): use of a cluster-size threshold. Magnetic Resonance in Medicine, 33 (1995), pp. 636-647

Fujii et al., 2000

T. Fujii, M. Moscovitch, L. Nadel. Memory consolidation, retrograde amnesia, and the temporal lobe. Cermak (Ed.), Handbook of neuropsychology (2nd ed.), Elsevier, Amsterdam (2000), pp. 233-250

Gorno Tempini et al., 1998

M.L. Gorno Tempini, C.J. Price, O. Josephs, R. Vandenberghe, S.F. Cappa, N. Kapur, et al. The neural systems sustaining face and propername processing. Brain, 121 (1998), pp. 2103-2118

Haist et al., 2001

F. Haist, G.J. Bowden, H. Mao. Consolidation of human memory over decades revealed by functional magnetic resonance imaging. Nature Neuroscience, 4 (2001), pp. 1139-1145

Hodges et al., 2000

J.R. Hodges, S. Bozeat, M.A. Lambon Ralph, K. Patterson, J. Spatt. The role of conceptual knowledge in object use evidence from semantic dementia. Brain, 123 (Pt 9) (2000), pp. 1913-1925

[Neuropsychologia, Vol 43, No. 5 (2005): pg. 693-703. DOI. This article is (C) Elsevier and permission has been granted for this version to appear in e-Publications@Marquette. Elsevier does not grant permission for this article to be further copied/distributed or hosted elsewhere without the express permission from Elsevier.] 
NOT THE PUBLISHED VERSION; this is the author's final, peer-reviewed manuscript. The published version may be accessed by following the link in the citation at the bottom of the page.

Kapur et al., 1995

N. Kapur, K.J. Friston, A. Young, C.D. Frith, R.S. Frackowiak.

Activation of human hippocampal formation during memory for faces:

a PET study. Cortex, 31 (1995), pp. 99-108

Kim et al., 2000

J.J. Kim, B. Crespo-Facorro, N.C. Andreasen, D.S. O'Leary, B. Zhang, G. Harris, et al. An MRI-based parcellation method for the temporal lobe. Neuroimage, 11 (2000), pp. 271-288

Kopelman, 2000

M.D. Kopelman. Neuropsychology of remote memory. Cermak (Ed.), Handbook of Neuropsychology (2nd ed.), Elsevier, Amsterdam (2000), pp. 251-280

Leveroni et al., 2000

C.L. Leveroni, M. Seidenberg, A.R. Mayer, L.A. Mead, J.R. Binder, S.M. Rao. Neural systems underlying the recognition of familiar and newly learned faces. Journal of Neuroscience, 20 (2000), pp. 878-886

Maddock et al., 2001

R.J. Maddock, A.S. Garrett, M.H. Buonocore. Remembering familiar people: the posterior cingulate cortex and autobiographical memory retrieval. Neuroscience, 104 (2001), pp. 667-676

Maguire and Frith, 2003

E.A. Maguire, C.D. Frith. Lateral asymmetry in the hippocampal response to the remoteness of autobiographical memories. Journal of Neuroscience, 23 (2003), pp. 5302-5307

Maguire et al., 2001

E.A. Maguire, R.N. Henson, C.J . Mummery, C.D. Frith. Activity in prefrontal cortex, not hippocampus, varies parametrically with the increasing remoteness of memories. Neuroreport, 12 (2001), pp. 441444

Maylor, 1990

E.A. Maylor. Recognizing and naming faces: aging, memory retrieval, and the tip of the tongue state. J ournal of Gerontology: Psychological Sciences, 45 (1990), pp. 215-226

Nadel and Moscovitch, 1997

L. Nadel, M. Moscovitch. Memory consolidation, retrograde amnesia and the hippocampal complex. Current Opinion in Neurobiology, 7 (1997), pp. 217-227

Niki and Luo, 2002

K. Niki, J. Luo. An fMRI study on the time-limited role of the medial temporal lobe in long-term topographical autobiographic memory. J ournal of Cognitive Neuroscience, 14 (2002), pp. 500-507

[Neuropsychologia, Vol 43, No. 5 (2005): pg. 693-703. DOI. This article is (C Elsevier and permission has been granted for this version to appear in e-Publications@Marquette. Elsevier does not grant permission for this article to be further copied/distributed or hosted elsewhere without the express permission from Elsevier.] 
NOT THE PUBLISHED VERSION; this is the author's final, peer-reviewed manuscript. The published version may be accessed by following the link in the citation at the bottom of the page.

Oldfield, 1971

R.C. Oldfield. The assessment and analysis of handedness: the Edinburgh inventory. Neuropsychologia, 9 (1971), pp. 97-113

Piefke et al., 2003

M. Piefke, P.H. Weiss, K. Zilles, H.J. Markowitsch, G.R. Fink.

Differential remoteness and emotional tone modulate the neural correlates of autobiographical memory. Brain, 126 (2003), pp. 650668

Pigott and Milner, 1993

S. Pigott, B. Milner. Memory for different aspects of complex visual scenes after unilateral temporal- or frontal-lobe resection.

Neuropsychologia, 31 (1993), pp. 1-15

Randolph, 1998

Randolph, C. (1998). Repeatable Battery for the Assessment of Neuropsychological Status. San Antonio: The Psychological Corporation.

Randolph et al., 1998

C. Randolph, M.C. Tierney, E. Mohr, T.N. Chase. The repeatable battery for the assessment of neuropsychological status (RBANS): preliminary clinical validity. J ournal of Clinical and Experimental Neuropsychology, 20 (1998), pp. 310-319

Rempel-Clower et al., 1996

N.L. Rempel-Clower, S.M. Zola, L.R. Squire, D.G. Amaral. Three cases of enduring memory impairment after bilateral damage limited to the hippocampal formation. Journal of Neuroscience, 16 (1996), pp. 52335255

Ryan et al., 2001

L. Ryan, L. Nadel, K. Keil, K. Putnam, D. Schnyer, T. Trouard, et al. Hippocampal complex and retrieval of recent and very remote autobiographical memories: evidence from functional magnetic resonance imaging in neurologically intact people. Hippocampus, 11 (2001), pp. 707-714

Seidenberg et al., 2002

M. Seidenberg, R. Griffith, D. Sabsevitz, M. Moran, A. Haltiner, B. Bell, et al. Recognition and identification of famous faces in patients with unilateral temporal lobe epilepsy. Neuropsychologia, 40 (2002), pp. 446- 456

Sergent et al., 1992

J. Sergent, S. Ohta, B. MacDonald. Functional neuroanatomy of face \& object processing. A position emission study. Brain, 115 (1) (1992), pp. 13-36J . Sergent, E. Zuck, S. Terriah, B. MacDonald. Distributed neural network underlying musical sight-reading and keyboard performance. Science, 257 (1992), pp. 106-109

[Neuropsychologia, Vol 43, No. 5 (2005): pg. 693-703. DOI. This article is (C Elsevier and permission has been granted for this version to appear in e-Publications@Marquette. Elsevier does not grant permission for this article to be further copied/distributed or hosted elsewhere without the express permission from Elsevier.] 
NOT THE PUBLISHED VERSION; this is the author's final, peer-reviewed manuscript. The published version may be accessed by following the link in the citation at the bottom of the page.

Shah et al., 2001

N.J. Shah, J.C. Marshall, O. Zafiris, A. Schwab, K. Zilles, H.J.

Markowitsch, et al. The neural correlates of person familiarity. A

functional magnetic resonance imaging study with clinical implications.

Brain, 124 (2001), pp. 804-815

Squire and Alvarez, 1995

L.R. Squire, P. Alvarez. Retrograde amnesia and memory

consolidation: a neurobiological perspective. Current Opinion in

Neurobiology, 5 (1995), pp. 169-177

Talairach and Tournoux, 1988

$\mathrm{J}$. Talairach, P. Tournoux. Co-planar stereotaxic atlas of the human

brain. Thieme, New York (1988)

Tsukiura et al., 2002

T. Tsukiura, T. Fujii, J. Okuda, H. Ohtake, R. Kawashima, M. Itoh, et al. Time-dependent contribution of the hippocampal complex when remembering the past: a PET study. Neuroreport, 13 (2002), pp.

2319-2323

Viskontas et al., 2002

I.V. Viskontas, M.P. McAndrews, M. Moscovitch. Memory for famous people in patients with unilateral temporal lobe epilepsy and excisions. Neuropsychology, 16 (2002), pp. 472-480

Wahlin et al., 1993

A. Wahlin, L. Backman, T. Mantyla, A. Herlitz, M. Viitanen, B. Winblad. Prior knowledge and face recognition in a community-based sample of healthy, very old adults. J ournal of Gerontology: Psychological Sciences, 48 (1993), pp. P54-P61

Westmacott et al., 2004

R. Westmacott, S.E. Black, M. Freedman, M. Moscovitch. The contribution of autobiographical significance to semantic memory: evidence from Alzheimer's disease, semantic dementia, and amnesia. Neuropsychologia, 42 (2004), pp. 25-48

Westmacott and Moscovitch, 2003

R. Westmacott, M. Moscovitch. The contribution of autobiographical significance to semantic memory. Memory and Cognition, 31 (2003), pp. $761-774$

[Neuropsychologia, Vol 43, No. 5 (2005): pg. 693-703. DOI. This article is (C Elsevier and permission has been granted for this version to appear in e-Publications@Marquette. Elsevier does not grant permission for this article to be further copied/distributed or hosted elsewhere without the express permission from Elsevier.] 